\title{
Perception of lateral movement by monocularly viewing pigeons*
}

\author{
MICHAEL C. CORBALLIS and LORENZ LUTHE \\ McGill University, Montreal, Quebec, Canada
}

\begin{abstract}
Eight pigeons were tested for head nystagmus in a rotating drum with vertical black and white bars on the inside. When the birds viewed monocularly, they gave about four times as many responses to nasalward as to temporalward movement. However, no such asymmetry was observed in a discrimination paradigm. Six pigeons were taught binocularly to discriminate moving lines, which moved equally of ten to left and right, from stationary lines. They were then tested monocularly. and the discrimination was controlled about equally by nasalward and temporalward movement.
\end{abstract}

Monocularly viewing pigeons show much more pronounced nystagmus to nasalward than to temporalward movement. For example, a pigeon viewing with its right eye shows strong nystagmus of the head and eyes if it is placed in a field of stripes moving to the left, but little or no nystagmus if the stripes move to the right (Huizinga \& van der Meulen, 1951). A similar asymmetry in nystagmus responses to monocular stimulation has been reported in other species as well, including several from among the mammals, reptiles, and birds (Tauber \& Atkin, 1968).

One question that arises is whether this asymmetry applies generally to the monocular perception of lateral movement or whether it is restricted to the nystagmus response. For example, would nasalward and temporalward movement exert equal stimulus control in a discrimination-learning paradigm? A study by Mello (1968) is perhaps tangentially relevant to this question: she taught monocularly viewing pigeons to discriminate leftward from rightward movement. When the birds were then tested with the untrained eye, they either failed to discriminate the two directions or they reversed the original discrimination; for example, if they had been trained to respond to leftward movement but not to rightward movement, they would now respond more to rightward than to leftward movement. This reversal could conceivably be due to differential perception of the two directions. Suppose, for example, that a pigeon viewing with its right eye perceives leftward movement more clearly than rightward movement. This differential clarity could form the basis of the discrimination. When the bird views with its left eye, then, it would now be the rightward movement which is the more clearly perceived, and so the discrimination is reversed. Mello (1968) argued against this interpretation on the grounds that there were no apparent differences in performance depending upon which eye was open during training, even though the positive stimulus ( $\mathrm{S}+$ ) was lefward

*This research was supported by the National Research Council of Canada. motion and the negative stimulus ( $-\rightarrow$ ) was rightward motion for all birds. However, it is not clear to us that one would have expected differential performance, at least to any marked degree.

The main purpose of the present study was to compare the stimulus-control properties of nasalward and temporalward movement in monocularly viewing pigeons after they had been taught binocularly to discriminate moving stripes from stationary stripes. During the binocular training, both directions of motion were presented equally often and were equally associated with reinforcement. The question was whether there would be any differential response to nasalward and temporalward motion during the monocular test trials.

We also present data on head nystagmus, principally to determine whether the asymmetry between nasalward and temporalward motion holds when the pigeons wear goggles restricting vision to the anterior visual field, as they did in the discrimination phase of the present study as well as in Mello's (1968) experiment. This point also has some intrinsic interest, since there is evidence that vision in this anterior field is of a different type from that in the lateral fields; the anterior field is probably binocular, myopic, and restricted to about $24 \mathrm{deg}$ of visual angle, while lateral vision is monocular, hyperopic, and panoramic (Catania, 1964). Moreover, Fite (1968) has demonstrated two different kinds of nystagmus in the pigeon: stare nystagmus, which occurs when the majority of contours in the field are moving in the same direction, and look nystagmus, which is elicited by a single contour and serves apparently to maintain foveal fixation of a single moving object. Our procedure for eliciting nystagmus, like that of Huizinga and van der Meulen (1951), would have favored stare nystagmus. Fite (1968) suggested that stare nystagmus might be important in flight, when the entire panorama of the visual field contains moving contours. If so, then we might expect some reduction of the nystagmus response when vision is restricted to the anterior field. Finally, Tauber and Atkin (1968) suggested that the predominance of nasalward over temporalward nystagmus might be restricted to species with afoveate 
retinal organization. They cite the pigeon as one example of such a species, even though the pigeon does, in fact, appear to possess a single fovea in each eye. Nevertheless, it is perhaps pertinent to note that the fovea is placed centrally on the retina, and is therefore not stimulated by the anterior field (Chard \& Gundlach, 1938). Conceivably, then, we might expect the dominance of nasalward over temporalward nystagmus to be more pronounced when vision is restricted to the anterior field than when it is not.

\section{METHOD}

\section{Head Nystagmus}

\section{Subjects}

Eight male White Carneaux pigeons (Columbia livia) served.

\section{Apparatus}

During an observation session, each bird was placed in a cylinder, $50 \mathrm{~cm}$ deep and $75 \mathrm{~cm}$ in diam, which could be rotated in either direction at a rate of $14 \mathrm{rpm}$. The inside of the cylinder was painted white, and 63 black vertical bars of tape, $2 \mathrm{~cm}$ wide, were stuck at equal distances around the inside curved surface. When the cylinder was in motion, then, the stripes moved past a fixed point at about $14.7 / \mathrm{sec}$. The pigeon was held in the apparatus by means of a plastic sleeve, which permitted its head but not the rest of its body to move. The bird's head was then about $30 \mathrm{~cm}$ from the moving stripes and about $17 \mathrm{~cm}$ from the base of the drum.

\section{Procedure}

Each observation session lasted 45 sec. Nystagmus movements of the head were counted, at first by two different Os, but, since they were almost always in perfect agreement, most of the observations were done by a single $O$. A nystagmus movement is easy to detect; it consists of a slow head movement in the direction of the moving stripes, followed by a quick movement in the opposite direction.

During some of the observations, the birds wore goggles similar to those described by Corballis and Beale (1970). These were made from cylindrical opaque bottle caps, $14 \mathrm{~cm}$ in diam and cut to a 5-mm length. A window, $10 \mathrm{~mm}$ long, was cut from one side of the curved surface. When attached with dental acrylic over the bird's eye, with the window facing forwards, the goggle prevented lateral vision, but allowed the bird to see forwards with no nasal obstruction. An opaque plastic occluder could be fitted into the window to prevent the bird from seeing with that eye.

The pigeons were tested binocularly and with each eye separately, with and without goggles. Under each of these six conditions, the birds were given six 45-sec test sessions, three with leftward and three with rightward motion. All birds were tested under all conditions (a total of 36 sessions), except that one (S 7) died before it could be tested with its right eye open, ungoggled. Testing was done on separate days to allow postrotary nystagmus to dissipate (cf. Huizinga \& van der Meulen, 1951).

\section{Discrimination of Lateral Motion}

\section{Subjects}

Six male White Carneaux pigeons served. Three of these also provided data on head nystagmus. During this phase of the experiment, the birds were maintained at about $80 \%$ of free-feeding weight.

\section{Apparatus}

Training and testing were carried out in a single-key pigeon chamber (Ferster \& Skinner, 1957). The front panel contained a rectangular translucent key, $8 \mathrm{~cm}$ wide $\times 7.5 \mathrm{~cm}$ high, hinged on the upper edge and located $7.5 \mathrm{~cm}$ above a grain magazine. Stimuli were projected onto the key from behind.

The stimuli were constructed from sample slides made from double refracting material, which simulated motion when projected through a rotating polarized disk (materials supplied by Edmund Scientific Co., Barrington, New Jersey, Stock Nos. 70950-70963). The display on the key consisted of vertical bars ranging from white to deep blue, with every 10 th bar the same color, to give the effect of a sinusoidal blue-and-white grating. When the polarized disk was rotated, the grating moved horizontally at $6.4 \mathrm{~cm} / \mathrm{sec}$. Note that this is apparent motion rather than real motion, since there is no actual motion within each $3-\mathrm{mm}$ bar. Nevertheless, the motion is convincing to the human eye; moreover, Siegel (1971) has shown strong equivalence between real and apparent motion in pigeons, using apparent motion displays of considerably coarser "grain" than those of the present study.

Several different moving displays were used, but all were rectangular and involved lateral movement of vertical gratings, as described above. Some displays occupied the whole width of the key, others were narrower, though none was less than half the width of the key. The displays also varied in height.

Reinforcements consisted of access to grain for $5 \mathrm{sec}$ in a lighted magazine. The key was darkened during reinforcement. White noise was used throughout to mask extraneous sounds. Stimulus events were programmed by relays, tape programmers, and timers, and responses were recorded on counters.

\section{Procedure}

Prior to discrimination training, the birds were taught to peck a lighted key for reinforcement. Reinforcement was first given following every peck, but the schedule was gradually altered until reinforcements occurred only following the first peck that occurred after some variable interval averaging $1 \mathrm{~min}$ from the previous reinforcement (VI 1).

The birds were then fitted with goggles (as described above) over both eyes, and discrimination training began. Viewing was binocular. The different stimuli were presented for intervals of $1 \mathrm{~min}$, followed by a 7-sec time-out interval during which the key was dark. Discriminative stimuli consisted of left-moving, right-moving, or stationary gratings; stationary gratings were presented by simply stopping the polarized disk, such that the grating could be in any possible position relative to the display area on the key. The stimuli were presented in pseudorandom sequence, subject to the following restrictions: (a) moving stimuli were presented as often as stationary ones, (b) left-moving and right-moving gratings appeared equally of ten, (c) neither a moving nor a stationary stimulus could occur more than three times in succession.

For three of the birds, the reinforced stimuli $(S+)$ were the moving ones, while the unreinforced ones $\left(S_{-}\right)$were the stationary ones. For the other three, it was the stationary stimuli that were reinforced, while the moving ones were not. Reinforcement during $S+$ was administered immediately following the first peck after varying intervals from the previous reinforcement. On different daily sessions, each lasting about $1 \mathrm{~h}$, these varying intervals were increased in average value, starting from $10 \mathrm{sec}$ in the first few sessions, though $30 \mathrm{sec}$, to $1 \mathrm{~min}$ by the fifth or sixth session (VI $10 \mathrm{sec}$, to VI $30 \mathrm{sec}$, to VI $1 \mathrm{~min})$. Discrimination training was continued until each bird made fewer than $10 \%$ of its daily responses to $S$ - 
During test sessions, the birds viewed monocularly instead of binocularly. The stimuli were presented exactly as during training, but no reinforcements were given. Each test session lasted $30 \mathrm{~min}$. Each bird received two test sessions, one while viewing with the tight eye and one while viewing with the left eye.

\section{RESULTS}

\section{Head Nystagmus}

With binocular viewing, good nystagmus was observed both when the birds were goggled and when they were not; the mean numbers of responses were 131.4 and 195.6, respectively (which did not differ significantly). The percentage of responses to leftward motion was also computed for each bird, and the means were 50.8 when they were goggled and 50.3 when they were not. Clearly, then, there was no bias in favor of one or the other direction of motion.

With monocular viewing, the mean numbers of nystagmus responses were, for the left eye, 126.4 and 154.9 for goggled and ungoggled viewing, respectively, and for the right eye, 143.1 and 124.1 for goggled and ungoggled viewing, respectively. There were no statistically significant differences among these means.

Table 1 shows the proportions of responses that each bird made to nasalward movement while viewing with each eye, both when goggled and when ungoggled. For all birds, under all conditions, these proportions were greater than .5 , confirming that head nystagmus is at least more frequent to nasalward than to temporalward motion. Analysis of variance of these proportions, omitting those for S 7, whose data were incomplete, revealed that the average proportion of .785 was significantly greater than $.5, F(1,6)=93.3, p<.001$, but that there were no significant differences associated with eyes or with whether the birds wore goggles or not.

\section{Discrimination of Lateral Motion}

The results of the test trials are summarized in Table 2, which shows the proportions of responses to

Table 1

Proportion of Nystagmus Responses to Nasalward Motion

\begin{tabular}{lccccc} 
& \multicolumn{2}{c}{ Ungoggled } & & \multicolumn{2}{c}{ Goggled } \\
\cline { 2 - 3 } Bird & $\begin{array}{c}\text { Left } \\
\text { Eye }\end{array}$ & $\begin{array}{c}\text { Right } \\
\text { Eye }\end{array}$ & & $\begin{array}{c}\text { Left } \\
\text { Eye }\end{array}$ & $\begin{array}{c}\text { Right } \\
\text { Eye }\end{array}$ \\
\hline S4 & .70 & .94 & .91 & .98 \\
S5 & .87 & .71 & .79 & .52 \\
S10 & .83 & .66 & .87 & .61 \\
S11 & .70 & .71 & .85 & .60 \\
S12 & .74 & .61 & .71 & .80 \\
S13 & 1.00 & .95 & .66 & .88 \\
S14 & .82 & .83 & .87 & .87 \\
S7 & .99 & - & .93 & .77 \\
Mean & .831 & .773 & .824 & .754 \\
\hline
\end{tabular}

Table 2

Proportion of Monocular Test Responses to Nasalward Motion (N), Temporalward Motion (T), and Stationarity (S)

\begin{tabular}{|c|c|c|c|c|c|c|}
\hline \multirow[b]{2}{*}{ Bird } & \multicolumn{3}{|c|}{ Left Eye } & \multicolumn{3}{|c|}{ Right Eye } \\
\hline & $\mathrm{N}$ & $\mathrm{T}$ & S & $\mathbf{N}$ & $\mathbf{T}$ & $\mathbf{S}$ \\
\hline & \multicolumn{6}{|c|}{ (a) Movement (S+) vs Stationarity (S-) } \\
\hline $\begin{array}{l}\text { S7 } \\
\text { S10 } \\
\text { S12 }\end{array}$ & $\begin{array}{l}.347 \\
.497 \\
.430\end{array}$ & $\begin{array}{l}.592 \\
.485 \\
.566\end{array}$ & $\begin{array}{r}.061 \\
.018 \\
.004\end{array}$ & $\begin{array}{l}.541 \\
.458 \\
.591\end{array}$ & $\begin{array}{r}.410 \\
.519 \\
.406\end{array}$ & $\begin{array}{l}.049 \\
.023 \\
.003\end{array}$ \\
\hline \multirow[t]{2}{*}{ Mean } & .425 & .548 & .027 & .530 & .445 & .025 \\
\hline & \multicolumn{6}{|c|}{ Stationarity (S } \\
\hline $\begin{array}{l}\text { S2 } \\
\text { S3 } \\
\text { S4 }\end{array}$ & $\begin{array}{l}.006 \\
.221 \\
.084\end{array}$ & $\begin{array}{l}.009 \\
.141 \\
.077\end{array}$ & $\begin{array}{l}.984 \\
.638 \\
.839\end{array}$ & $\begin{array}{l}.003 \\
.121 \\
.098\end{array}$ & $\begin{array}{l}.003 \\
.146 \\
.166\end{array}$ & $\begin{array}{l}.995 \\
.732 \\
.736\end{array}$ \\
\hline Mean & .104 & .076 & .820 & .074 & .105 & .821 \\
\hline
\end{tabular}

nasalward and temporalward movement and to the stationary-grating, for each bird viewing with each eye. The numbers of responses on which these proportions are based ranged from 49 to 778 .

First, it is clear that the discrimination between moving and stationary gratings was maintained in monocular testing, even though the training was binocular. Four of the six birds still easily surpassed the discrimination criterion of less than $10 \%$ of responses to $\mathrm{S}-$.

Secondly, there are no systematic differences depending on whether the movement was nasalward or temporalward. Consider the birds for whom movement constituted the $\mathrm{S}+$ and stationarity the $\mathrm{S}-$. If temporalward motion is in some sense less clearly perceived than nasalward motion, one might have expected relatively fewer responses to it. The difference was actually slightly, but insignificantly, in the opposite direction; the mean proportion of responses to temporalward motion was .50 , that to nasalward motion, .48 .

If responses to motion only are considered, the mean proportion to nasalward motion was .49 . The same three birds gave a mean proportion of .78 of their nystagmus responses to nasalward motion when viewing through a goggle. These two proportions differ significantly, $t(2)=$ $6.6, \mathrm{p}<.05$.

For the remaining three birds, who were trained with stationarity as the $\mathrm{S}+$ and movement as the $\mathrm{S}-$, one might possibly expect more responses to temporalward than to nasalward motion if it is supposed that temporalward motion is perceived as "more like" stationarity. However, the difference was, in fact, negligible and insignificant; the mean proportions were .090 and .089 to temporalward and nasalward motion, respectively.

\section{DISCUSSION}

First, the data on head nystagmus show that, in a pigeon viewing monocularly, nasalward movement elicits about four times as many responses as does 
temporalward movement, confirming the asymmetry reported by Huizinga and van der Meulen (1951). The incidence of nystagmus was only slightly and insignificantly reduced when vision was restricted to the anterior field, which shows at least that it does not depend on stimulation of the lateral visual system (cf. Fite, 1968). Further, the predominance of nasalward over temporalward nystagmus occurred about equally when vision was and was not restricted, and therefore did not depend on whether or not the fovea was stimulated (cf. Tauber \& Atkin, 1968). It would be of interest, however, to extend these observations by investigating nystagmus when vision is restricted to the lateral field.

In marked contrast, results from the discrimination phase of the experiment revealed no evidence for any consistent asymmetry in the stimulus-control properties of nasalward and temporalward movement. It cannot plausibly be argued that the discrimination procedure itself acted to override any initial asymmetry in monocular perception of motion, because the discrimination was carried out with binocular viewing. In any case, for those birds which participated in both phases of the experiment, the discrimination phase actually preceded the nystagmus phase. It is, of course, conceivable that the discrimination procedure was somehow too insensitive to reveal subtle perceptual effects, or that apparent movement is perceived differently from real movement (despite Siegel's, 1971, evidence to the contrary), or that other parameters, such as distance, speed, or spatial frequency, crucially determine whether there is asymmetry or not. We think it more likely that the mechanisms underlying the asymmetry in the nystagmus response are simply quite separate from those involved in discrimination learning.

Our results also suggest that the interocular mirror-image reversal effect reported by Mello (1968) cannot be attributed to any asymmetry in the stimulus-control properties of nasalward and temporalward movement. This effect probably depends on how a monocularly viewing pigeon interprets the direction of lateral movement. For example, reversal is predicted if the pigeon codes the two directions as towards or away from the beak. An alternative explanation of Mello's (1968) data makes no reference at all to lateral motion. She used stimulus displays that consisted of vertical stripes moving laterally behind a transparent circular key. The boundaries of the key would therefore have caused the stripes to appear to expand vertically as they crossed the first half of the key, and then to contract as they crossed the second half. (This was not the case in our experiment, in which the stimulus displays were rectangular.) There is also evidence that a monocularly viewing pigeon tends to focus attention on one side of the key, the side of the seeing eye (Beale \& Corballis, 1968; Corballis \& Beale, 1970). Therefore, the discrimination in Mello's experiment could have been based on expansion vs contraction, which would also predict reversal when viewing is switched from one eye to the other.

\section{REFERENCES}

Beale, I. L., \& Corballis, M. C. Beak shift: An explanation for interocular mirror-image reversal in pigeons. Nature, London, $1968,220,82 \cdot 83$.

Catania, A. C. On the visual acuity of the pigeon. Journal of the Experimental Analysis of Behavior, 1964, 7, 361-366.

Chard, R. D., \& Gundlach, R. H. The structure of the eye of the homing pigeon. Journal of Comparative Psychology. 1938, 25. 249-272.

Corballis, M. C.. \& Beale, I. L. Monocular discrimination of mirror-image obliques by pigeons: Evidence for lateralized stimulus control. Animal Behaviour, 1970, 18. 563-566.

Ferster, C. B., \& Skinner, B. F. Schedules of reinforcement. New York: Appleton-Century-Crofts, 1957.

Fite, K. V. Two types of optomotor response in the domestic pigeon. Journal of Comparative \& Physiological Psychology, $1968,66,308-314$

Huizinga, E., \& van der Meulen, P. Vestibular rotatory and opto-kinetic reactions in the pigeon. Annals of Otology \& Laryngology, 1951, 60, 927-947.

Mello, N. K. Interhemispheric transfer of a discrimination of moving patterns in pigeon. Brain Research, 1968, 7, 390-398.

Siegel, R. K. Apparent movement and real movement detection in the pigeon: Stimulus generalization. Journal of the Experimental Analysis of Behavior, 1971, 16, 189-192.

Tauber, E. S., \& Atkin, A. Optomotor responses to monocular stimulation: Relation to visual system organization. Science, 1968, 160, 1365-1367.

(Received for publication December 22, 1972; revision received March 15, 1973.) 